\title{
Hemodynamic monitoring during cardiac surgery in France: a multicentric prospective study.
}

Bonnet V, M.D. ${ }^{1,2}$; D’Orlando R¹ ; Dechanet F, M.D. ${ }^{1}$; Babatasi G, M.D. ${ }^{3}$; Gérard JL, M.D. ${ }^{1,2}$; Hanouz JL, M.D., Ph.D. ${ }^{1,2,4}$; Fischer MO, M.D., Ph.D. ${ }^{1,4}$; and the EMOA study group for the ARCOTHOVA.

${ }^{1}$ Department of Anaesthesiology and Critical Care, University Hospital of Caen, 14033 Caen, France

2 Unicaen, Normandie Univ, 14000 Caen, France

${ }^{3}$ Cardiac Surgery Department, University Hospital of Caen, 14033 Caen, France

4 EA 4650, Normandie Univ, Université de Caen Basse-Normandie, Esplanade de la Paix, CS 14 032, F-14 000 Caen, France

\section{BACKGROUND AND GOAL OF STUDY}

New monitoring systems and inotropic drugs, developed in the past decade, have modified the hemodynamic management in cardiac surgery. However, only sparse data are available to reflect these changes and the last national inquiry in France was performed in 2005 (1). This study aimed at giving an up-to-date overview of advanced hemodynamic monitoring during cardiac surgery in France.

\section{MATERIAL AND METHODS}

Patient medical history, type of surgery, monitoring characteristics and postoperative outcomes were prospectively recorded for every patient who underwent cardiac surgery in any of the 37 participating centers, on an inclusion period of seven weeks. Primary objective was the description of advanced monitoring and inotropes/vasoactives drugs use. Secondary outcome was to assess the influence of monitoring on post-operative outcomes.

\section{RESULTS}

\section{1) Advanced hemodynamic monitoring use}

During the inclusion period, 3100 patients underwent cardiac surgery. Among them, 1656 (53.4\%) beneficiated from advanced hemodynamic monitoring, including cardiac output measurement and/or metabolic balance assessment. Table 1 shows the different devices used for monitoring.

\begin{tabular}{|c|c|}
\hline Device & $\begin{array}{c}\text { Number of Patients } \\
\text { (Percentage) }\end{array}$ \\
\hline $\begin{array}{c}\text { Transoesophageal Sonography } \\
\text { Metabolic Balance } \\
\text { (Sv02 or Scv02) }\end{array}$ & $1139(37 \%)$ \\
\hline Thermodilution (Swann-Ganz) & $691(22 \%)$ \\
\hline Pulse Contour & $370(12 \%)$ \\
\hline Oesophagal Doppler & $32(1 \%)$ \\
\hline Impedancemetry & $14(0,5 \%)$ \\
\hline Table 1 & $3(0,1 \%)$ \\
\hline
\end{tabular}

Some pre-operatives conditions were significantly associated with use of monitoring, such as Left-Ventricular Ejection Fraction impairment, pre-operative kidney failure, anemia, patients who underwent combined (valvular and coronary) surgery, or in emergency situations. The mean Euroscore II was higher for the monitored patients $(4.7+/-7.5 \mathrm{vs} 3.3+/-5.2$, $\mathrm{p}<.001)$

\section{2) Inotropes and vasoactives drugs use}

The use of per-operative inotropes and vasoactives drugs is described in figure $1.1693(54,6 \%)$ patients received at least one vasoactive medication.

\section{Figure IIntra-Operative Drug Use( \%)}

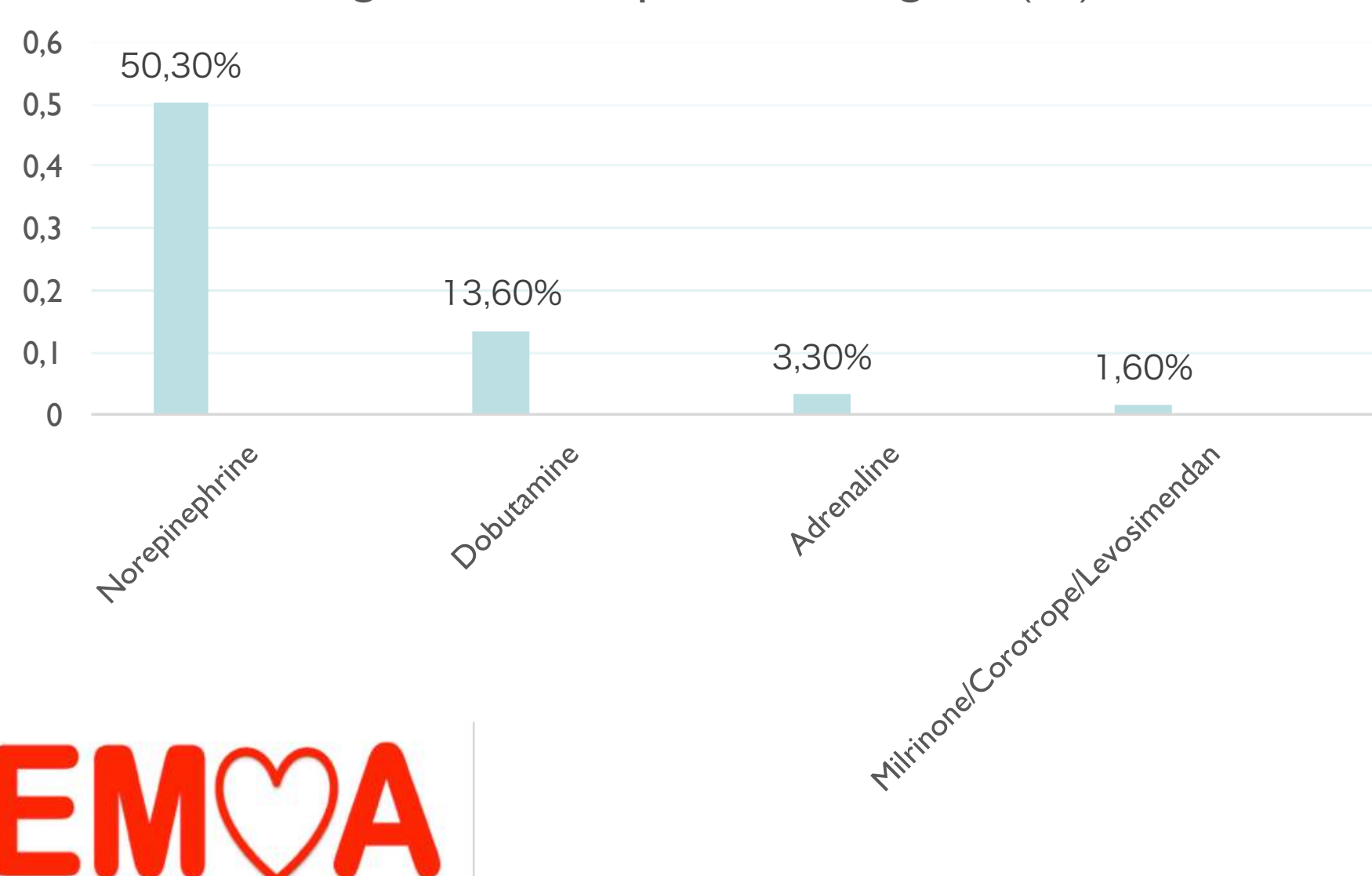

\section{3) Outcome}

The group of monitored patients had higher mortality, higher Euroscore II, and a higher rate of complications (Table 2 ).

\begin{tabular}{|c|c|c|c|}
\hline Advanced Mlonitoring & Yes & No & P \\
\hline Mortality (\%) & $\mathbf{5 , 1}$ & 2,3 & $<0,01$ \\
\hline Euroscore II (\%) & $\mathbf{4 , 7}$ & 3,3 & $<0,001$ \\
\hline $\begin{array}{c}\text { All Complications(\%) } \\
\text { Major Adverse Cardiac } \\
\text { and Cerebrovascular }\end{array}$ & $\mathbf{6 3 , 6}$ & 45,1 & $<0,001$ \\
$\begin{array}{c}\text { Event(\%) } \\
\text { Acute Renal Failure(\%) }\end{array}$ & $\mathbf{3 5 , 4}$ & 23,5 & $<0,001$ \\
\hline Table 2 & $\mathbf{2 6 , 8}$ & 13,8 & $<0,001$ \\
\hline
\end{tabular}

However, in the subgroup of octogenarians patients, though monitored patients had more serious preoperative condition (Euroscore II $7.5+/-$ 11.8 vs $5.0+/-6.1, p<.001$ ), they did not present more post-operative complications $(55.2 \%$ vs $48.6 \%, p=0.388)$ nor mortality $(6.1 \%$ vs $4.4 \%$, $\mathrm{p}=0.782$ ).

\section{DISCUSSION}

In our study, advanced hemodynamic monitoring was used for patients with higher preoperative risk without outcome improvement. However, it might be interesting for octogenarians patients, other studies for those specific population should be encouraged.

The most recent inotropic and vasoactives drugs were rarely used.

Norepinephrine is now the drug of choice, instead of dobutamine (1), maybe due to studies suggesting a potentially harmful overuse of dobutamine (2).

Unlike previous study (3), the Swann-Ganz catheter is no longer the first choice device. Transoesophagal sonography was often used. However, as morphological assessment during valvular surgery cannot be considered as hemodynamic monitoring, its use might be over-estimated.

\section{CONCLUSION}

Our study highlights changes in hemodynamic management of patients undergoing cardiac surgery, even if it was not associated with outcome improvement.

Other findings in our study support the hypothesis that specific subgroups of patients, such as elderly patients, may beneficiate more from advanced monitoring than others. 